\title{
Kritisch realisme en innovatie
}

\author{
Wat kan een kritisch-realistisch onderzoeksparadigma betekenen voor \\ verpleegkundig specialisten?
}

\section{Jan Sitvast}

Senior docent/onderzoeker a/d Hogeschool Utrecht. Instituut voor Verpleegkundige Studies, MANP. Vestigingsplaats: Utrecht (per 1 september 2020 met pensioen)

\section{Correspondentieadres}

jsitvast@gmail.com

\section{Samenvatting}

De rol van verpleegkundig specialisten in het realiseren van goede zorg impliceert een actieve inzet bij innovatie en onderzoek. Op deze rol worden verpleegkundig specialisten al tijdens hun opleiding voorbereid door het schrijven van hun master thesis. De kwaliteit van zorg roept de vraag op naar de aard van de kennis die daarvoor nodig is en ook hoe deze kennis tot stand komt. Na een filosofische beschouwing over de objectiviteit of de subjectiviteit van kennis wordt geponeerd dat het kritisch realisme een uitweg biedt uit deze discussie en bovendien een pragmatische benadering mogelijk maakt voor onderzoek ten behoeve van innovaties. Het kritisch realisme zullen we vertalen naar een praktisch model voor verpleegkundig specialisten die innovatie onderzoek doen. Het model zal geilllustreerd worden aan de hand van een praktijkvoorbeeld. Uiteindelijk zal de kritisch realistische onderzoekspraktijk recht doen aan de emancipatoire gedachte die in de gezondheidszorg en het kwaliteitsdenken sterk aanwezig is.

\section{Inleiding}

Het schrijven van een master thesis bereidt verpleegkundig specialisten i.o. voor op een beroepspraktijk waarin zij verantwoording dragen om goede zorg aan cliënten te geven, dus optimaal aan te sluiten op zorgbehoeften en zoveel mogelijk gebaseerd op evidence-based kennis. Behalve in individuele casuïstiek kan de vraag wat goede zorg is ook gesteld worden voor een doelgroep van patiënten. We komen dan op het terrein van innovatie. Wat goede zorg is gaat verder dan de instrumenteel-technische vraag naar effectiviteit en bewijskracht van evidence in onderzoek. Goede zorg voegt een waarde toe aan de kwaliteit van zorg die met betekenisgeving te maken heeft en wat mensen ervaren als goed in ontvangen zorg. Waar deze kwaliteit ontbreekt of als onvoldoende ervaren wordt, zal die waarde, ook waar het in eerste instantie gaat om zeer concrete uitkomsten, in het geding zijn en geëxpliciteerd moeten worden. Aan de hand van een praktijkvoorbeeld zullen we dit later in het artikel verduidelijken.

De kwaliteit van zorg vraagt om een 
kritische beschouwing waarin we soms tot de slotsom komen dat de uitkomst van goede zorg (indien aanwezig) emancipatoir genoemd mag worden. De zorg is emancipatoir als de zorgvrager centraal staat en er recht wordt gedaan aan het gegeven dat iemand een uniek persoon is die ook zelf richting aan zijn/haar leven geeft, ook m.b.t. de zorg die hij/zij nodig heeft. Dat betekent 'zorg op maat' passend bij de fase in de 'patient journey' (=zorgtraject dat de patiënt doorloopt in de tijd) en dat zowel zorgvrager en zorgverlener zoveel mogelijk een gelijkwaardige positie innemen. In die zin is emancipatoir ook 'vrijmakend': vrij van bevoogding (iemand anders-de dokter of de verpleegkundige- beslist voor jou) en stimulerend tot zelfzorg.

Kennis is niet waardenvrij want deze speelt een belangrijke rol in het aandragen van argumenten voor wat als goede zorg telt. Over wat goede zorg is kunnen patiënten en zorgverleners van mening verschillen. Wat voor de zorgverlener belangrijk is, wordt meestal beredeneerd vanuit geaggregeerde kennis die ook nog vaak gegoten is in instrumenteel-technisch jargon, dat lang niet altijd aansluit op de beleving van de patiënt. Dit kan de zorgverlener, i.c. de verpleegkundig specialist, ook parten spelen bij het bepalen van een richting voor innovatie. Bovendien roept het allerlei vragen op over wat wij als geldige kennis zien en welke kennisaanspraken vanuit het verpleegkundig domein hierin bepalend zijn. Het gaat verpleegkundig specialisten immers nooit alleen om medische kennis, maar veel meer om kennis over wat ziekte en aandoeningen betekenen voor het functioneren van de zieke in het dagelijks leven in een integratie van care en cure. Daarom zullen we eerst de fundamentele vraag stellen naar wat kennis is in de ziekenzorg om ons vervolgens af te vragen hoe deze kennis tot stand komt. Het antwoord zullen we vertalen naar een praktisch model dat leidend kan zijn bij innovatie onderzoek. Het model zal geïllustreerd worden aan de hand van een praktijkvoorbeeld.

\section{Hoe komt kennis tot stand?}

De betekenisgeving aan ervaringen is een belangrijk aspect van sociale processen en menselijk handelen. Dit is zeker aan de orde voor verpleegkundig specialisten, zoals we hierboven al vaststelden. $\mathrm{Nu}$ is de kennis van sociale processen en het menselijk handelen daarbinnen onderhevig aan tijdsgebonden en cultureel bepaalde inzichten. We kunnen spreken van een subjectieve en een objectieve realiteit. Betekenissen die we verlenen aan ziekte, genezing en herstel worden door mensen gedeeld en krijgen dan vaak een vanzelfsprekende geldigheid. De maatschappelijke betekenis wordt daarmee bijna een objectieve realiteit, die ook onderwerp is van de sociale wetenschap. Hoe de betekenis door individuen tot stand komt staat voor de subjectieve realiteit. In de wetenschap wordt al heel lang de discussie gevoerd over wat nu geldt als objectieve kennis versus subjectieve kennis. Er zijn theoretici die naar het standpunt neigen dat alle idee-vorming (kennis) over de sociale wereld bepaald wordt door de context en de tijd waarin we leven. Ze stellen dat er geen objectieve geldigheid ooit kan bestaan. Iets is waarheid wat mensen met elkaar op een gegeven moment en bepaalde plaats vinden. De plausibiliteit is dan belangrijker dan de objectiviteit, dus wat telt is hoe mensen taal gebruiken om de realiteit te construeren. Deze richting in de kennistheorie heet het sociaalconstructionisme (zie Figuur 1). Aanhangers van deze stroming in het denken stellen dat er niet een object is, ergens buiten ons ('out there') dat we 
kunnen observeren/bestuderen (zoals neopositivisten dat veronderstellen), maar dat betekenis a.h.w. 'onderhandeld' wordt in het proces van interpreteren. Andere onderzoekers werpen de sociaalconstructionisten echter voor de voeten dat elke ambitie om geldige kennis te verwerven door hen onmogelijk wordt en dat daarmee ook de dialoog die ook sociaal-constructionisten voorstaan op voorhand nutteloos wordt: alles is geldig, niets is meer geldig dan welke andere opvatting ook, dus waarom nog daarover met elkaar in gesprek gaan? Ook ethische concepten kunnen dan niet meer in stelling worden gebracht: 'empowerment' bijv. van patiënten. Dat ondermijnt uiteindelijk de emancipatoire gedachte die in de gezondheidszorg en het kwaliteitsdenken sterk aanwezig is.

Om dit doorgeslagen relativisme te corrigeren is een gezonde dosis realisme nodig. We moeten erkennen dat sociale fenomenen conceptueel gekend kunnen worden, dat wil zeggen dat er begrippen (concepten) zijn die de realiteit goed lijken te verklaren. Sommige concepten zijn meer 'waar' dan andere, dat is we kunnen de realiteit er beter mee begrijpen, zeker als er uit deze concepten betekenisvolle consequenties afgeleid kunnen worden die als 'redenen' om te handelen in stelling gebracht kunnen worden en in de beroepspraktijk gewenste uitkomsten veroorzaken $[1,2]$. Deze pragmatische benadering wordt wel het kritisch realisme genoemd (zie Figuur 1). De (kritisch-) realistische onderzoeker wil niet alleen kunnen verklaren dat er een causaal verband bestaat tussen oorzaken en uitkomsten, maar wil ook doorgronden hoe het werkt. Het is niet voldoende om het bestaan van sociale fenomenen te verklaren. Het is ook noodzakelijk de rationale die eraan ten grondslag ligt te begrijpen [2]. Bijvoorbeeld: zo zal vanuit een realistisch standpunt het niet genoeg zijn om van een bepaalde verpleegkundige interventie aan te tonen dat ze een positieve uitkomst (bijv. patiënten tevredenheid) geeft maar is het ook nodig om de weg (stappen) waarlangs de verbetering ontstaat te begrijpen.

Positivistische onderzoekers baseren hun onderzoek op het creëren van een gesloten systeem, een omgeving waarin interne en externe factoren gecontroleerd zijn, zodat geen onregelmatigheid optreedt die de uitkomsten beïnvloedt. Kritisch realistisch onderzoek heeft als doel het causale mechanisme te identificeren, dus vaststellen hoe het werkt en onder welke voorwaarden. Hiervoor is kwalitatief praktijkonderzoek nodig. De analyse van causaliteit vindt altijd plaats binnen een complex open systeem zoals in de gezondheidszorg nu eenmaal aan de orde is. Het doel van kritisch-realistisch onderzoek is om verschillende causale tendenties (i.p.v. een reductie tot één verklaring) in kaart te brengen in het systeem en men is zich bewust van de invloed van de context en van sociaal gedrag van actoren [2].

\section{$\underline{\text { Sociaal-constructionisme }}$}

Belangrijkste aannames:

kennis ontstaat door dialoog en uitwisseling tussen mensen en is dus 'geconstrueerd' en niet gegeven. Elke claim dat er objectieve criteria zouden zijn om tot geldige 'ware' kennis te kunnen komen, wordt afgewezen.

(neo-) positivisme

Belangrijkste aannames:

De realiteit is objectief kenbaar, d.w.z. er zijn causale verbanden tussen verschijnselen vast te stellen en patronen die algemeen geldig zijn en waarvan de verklaring slechts een kwestie is van het combineren en herleiden van de juiste data. 
Kritisch-realisme

Een emancipatoire theorie uit de sociale wetenschap die daar ontwikkeld is door Harré [3] en Bhaskar [4] en verwant is aan de 'kritische sociale wetenschap' van Habermas [5]. Deze benadering is volgens Delanty [6] zowel verklarend als interpreterend en verenigt deze met kritische sociale betrokkenheid ('critique'). Daardoor wordt het mogelijk om realisme, sociaal constructionisme en kritische emancipatoire theorie te combineren.

\begin{tabular}{|l|l|}
\hline $\begin{array}{l}\text { Sociaal- } \\
\text { constructionisme }\end{array}$ & $\begin{array}{l}\text { Belangrijkste aannames: } \\
\text { kennis ontstaat door dialoog en uitwisseling tussen mensen en is dus } \\
\text { 'geconstrueerd' en niet gegeven. Elke claim dat er objectieve criteria zouden zijn } \\
\text { om tot geldige 'ware' kennis te kunnen komen, wordt afgewezen. }\end{array}$ \\
\hline (neo-) positivisme & $\begin{array}{l}\text { Belangrijkste aannames: } \\
\text { De realiteit is objectief kenbaar, d.w.z. er zijn causale verbanden tussen } \\
\text { verschijnselen vast te stellen en patronen die algemeen geldig zijn en waarvan de } \\
\text { verklaring slechts een kwestie is van het combineren en herleiden van de juiste } \\
\text { data. }\end{array}$ \\
\hline Kritisch-realisme & $\begin{array}{l}\text { Een emancipatoire theorie uit de sociale wetenschap die daar ontwikkeld is door } \\
\text { Harré (1972) en Bhaskar (1975) en verwant is aan de 'kritische sociale wetenschap' } \\
\text { van Habermas (1987). Deze benadering is volgens Delanty (1997) zowel verklarend } \\
\text { als interpreterend en verenigt deze met kritische sociale betrokkenheid ('critique'). } \\
\text { Daardoor wordt het mogelijk om realisme, sociaal constructionisme en kritische } \\
\text { emancipatoire theorie te combineren }\end{array}$ \\
\hline
\end{tabular}

Figuur 1: kennistheoretische stromingen nader toegelicht

Vanuit een positivistisch vertrekpunt naar een kritisch realistisch standpunt

Wat is de relatie van bovengenoemde paradigma's met het proces van kennisverwerving door verpleegkundig specialisten i.o. tijdens de tweejarige Master Advanced Nursing Practice (MANP) opleiding? Studenten moeten in de loop van twee jaar eerst kennis verwerven voordat zij die situationeel en contextueel kunnen toepassen en kunnen interpreteren. $\mathrm{Zij}$ moeten bijvoorbeeld eerst kennis hebben van methoden en technieken van wetenschappelijk onderzoek voordat zij die kunnen plaatsen in de context van onderzoeksvragen uit de eigen beroepspraktijk. Er is in de leerontwikkeling een beweging van feiten leren, naar hoe ze deze moeten interpreteren vanuit verschillende perspectieven om deze vervolgens in hun beroepspraktijk in emancipatorische zin te gebruiken om de ontwikkeling van goede zorg mee te onderbouwen en te legitimeren. Van een meer positivistisch vertrekpunt (leren hoe het moet en hoe het is) dat aanleunt tegen het medisch denken naar een meer strategisch inzetten in de geest van kritisch realisme.

Van onderbouwing en legitimering van hun handelen naar vernieuwing In de module Evidence Based Practice (EBP) ligt het accent nog op het zoeken 
naar effectieve interventies en/of het aantonen van de effectiviteit, terwijl dit bij het praktijkgericht onderzoek voor de master thesis niet meer voldoende is en de toepasbaarheid en de klinische relevantie van de interventies bepalend wordt. Hoe daarin ook het perspectief van de verschillende 'stakeholders' (waaronder die van patiënten als belangrijkste) en processen van zin-en betekenisgeving een belangrijke rol spelen kunnen we linken aan de uitgangspunten van het sociaal constructionisme. Dat we toch steeds te maken hebben met een gegeven realiteit (overheidsbeleid, de organisatie waar men werkt, etc.) en een cultureel maatschappelijke context die van invloed is op de perceptie van ziekte en gezondheid, kan niet anders dan onderwerp van studie zijn voor verpleegkundig specialisten i.o. om meer kans van slagen te hebben bij innovaties. Dat is een kritisch realistisch uitgangspunt. Ook na de opleiding tot verpleegkundig specialist zal dit uitgangspunt van belang blijven. Immers verpleegkundig specialisten zullen in hun werk ook als innovator (wetenschap is één van de CanMedsrollen) actief zijn om op die manier beter in te spelen op de zorgbehoeften van hun patiënten [7]. Het kritisch realisme in de praktijk van innovatie(-onderzoek).

Ten behoeve van de MANP-opleiding en de beroepspraktijk kan het kritisch realistische standpunt uitgewerkt worden aan de hand van een aantal kernaspecten. Allereerst moet er een probleem worden geïdentificeerd. Om recht te doen aan de emancipatoire intentie van het kritisch realisme moet het probleem primair vanuit het patiënten perspectief worden beschreven (en daarna vanuit andere perspectieven, bijv. het organisatieperspectief). Er zal vastgesteld moeten worden welke wenselijke uitkomsten er zijn die nu (actueel) niet gerealiseerd kunnen worden. Dit gebeurt d.m.v. empirische observatie en praktijkonderzoek. Behalve niet gerealiseerde uitkomsten moeten er ook cruciale factoren worden vastgesteld die het probleem beïnvloeden. Vervolgens wordt gekeken of deze cruciale factoren gelinkt kunnen worden aan kern issues (de z.g. 'central issues'). De kern issues zijn de brug naar kritische concepten waarmee het probleem geduid kan worden en aannames (hypotheses) gedaan kunnen worden over de cruciale factoren die het probleem determineren (probleemanalyse). Deze centrale issues en kritische concepten zijn geabstraheerde theoretische inzichten en hebben daardoor een hypothetisch karakter. Ze moeten steeds weer naar de empirie vertaald worden en dus toegepast op een concreet probleem in de realiteit. Dit is een heen en weer pendelen tussen theorie en praktijk.

De actuele oplossing die gezocht wordt voor het probleem zal, vanuit een oogpunt van realisme, moeten aangrijpen op deze cruciale factoren. Met de interventie of benadering die in de onderzoeksliteratuur gevonden wordt, zal in de eerste plaats beoogd worden om de wenselijke uitkomsten op patiëntenniveau te realiseren waarvan eerder was vastgesteld dat ze niet of maar gedeeltelijk gerealiseerd waren. Om te kunnen onderbouwen dat de interventie geschikt is om de gewenste uitkomsten te realiseren zal in de literatuur ook onderzocht moeten worden en daarna verantwoord hoe de interventie dat feitelijk ('real') doet. Het werkingsmechanisme van de interventie zal moeten worden uitgelegd. Hier zal ook weer teruggegrepen worden op de 'central issues'en de kritische concepten (hypothese). Daarnaast moet er ook rekening gehouden worden met de actuele context waarbinnen de interventie uitgevoerd zal worden en met welke uitdagingen de hulpverlener te 
maken zal krijgen en tot slot welke potentiële mogelijkheden en kansen er liggen. Dat betekent dat een interventie die we tot nu toe alleen nog kennen uit de literatuur geactualiseerd moet worden naar de innovatiepraktijk. Dit is de ontwerpfase. We kunnen dit proces in een matrix
(Figuur 2) onderbrengen en daarbij gebruikmaken van de (Engelse) driedeling in 'actual', 'real' en 'real to actual', ontleend aan critical realism, aangevuld met 'hypothetical' en 'potential': zie matrix.

\begin{tabular}{|c|c|c|c|c|c|}
\hline & & $\begin{array}{l}\text { Empirische obs } \\
\text { Definiëring Prak } \\
\text { Onderzoeksfase: } \\
\text { Onderzoeksfase: } \\
\text { Onderzoeksfase: } \\
\text { Onderzoeksfase: }\end{array}$ & $\begin{array}{l}\text { tijkprobleem } \\
\text { Analyse van het pr } \\
\text { Zoeken naar een o } \\
\text { Ontwerpen van ee } \\
\text { Ontwerpen van eer }\end{array}$ & $\begin{array}{l}\text { obleem } \\
\text { plossing } \\
\text { innovatie } \\
\text { implementatieplan }\end{array}$ & en strategie \\
\hline Literatuur & $\begin{array}{l}\text { Literatuur en } \\
\text { praktijkonderzoek }\end{array}$ & Literatuuronderzoek & Literatuuronderzoek & $\begin{array}{l}\text { Literatuur en } \\
\text { praktijkonderzoek }\end{array}$ & $\begin{array}{l}\text { Literatuur en } \\
\text { praktijkonderzoek }\end{array}$ \\
\hline The hypothetical & The actual: & The real & The real: & $\begin{array}{l}\text { the transfer from the } \\
\text { real to the actual: }\end{array}$ & The potential \\
\hline $\begin{array}{l}\text { central issues and } \\
\text { critical concepts }\end{array}$ & $\begin{array}{l}\text { Outcomes= } \\
\text { Gewenste } \\
\text { uitkomsten } \\
\text { In terms of the initial } \\
\text { guiding question }\end{array}$ & De Interventie & $\begin{array}{l}\text { Mechanisme= } \\
\text { Hoe kan de } \\
\text { werkzaamheid van de } \\
\text { interventie verklaard } \\
\text { worden }\end{array}$ & $\begin{array}{l}\text { Context= } \\
\text { Conditions and } \\
\text { Necessities for } \\
\text { actualization }\end{array}$ & $\begin{array}{l}\text { Gaps and } \\
\text { opportunities, } \\
\text { possibilities or } \\
\text { potentials }\end{array}$ \\
\hline $\begin{array}{l}\text { Waar gaat } \\
\text { het om? }\end{array}$ & $\begin{array}{l}\text { Wat moet er } \\
\text { aan } \\
\text { uitkomsten } \\
\text { gerealiseerd } \\
\text { worden? }\end{array}$ & $\begin{array}{l}\text { Door welke } \\
\text { interventie of } \\
\text { benadering? }\end{array}$ & $\begin{array}{l}\text { Hoe wordt het } \\
\text { effect } \\
\text { (uitkomsten) } \\
\text { gerealiseerd? }\end{array}$ & $\begin{array}{l}\text { Wat zijn de } \\
\text { Condities waar } \\
\text { rekening mee } \\
\text { moet worden } \\
\text { gehouden in de } \\
\text { aanpassingen en } \\
\text { ontwerp van de } \\
\text { interventie? }\end{array}$ & $\begin{array}{l}\text { Welke Kansen } \\
\text { kunnen worden } \\
\text { benut? }\end{array}$ \\
\hline
\end{tabular}

Figuur 2: Fasen van onderzoek met proceskenmerken, sleutelbegrippen en kernvragen

\section{Praktijkvoorbeeld}

Met een praktijkvoorbeeld kunnen we het schema (matrix in Figuur 2) illustreren. Een verpleegkundig specialist, Agnes geheten, werkend op een poli voor ouderen met diabetes en hoge bloeddruk als comorbiditeit, ziet in haar praktijk dat psycho-educatie aan cliënten onvoldoende leidt tot de noodzakelijke aanpassingen van hun leefstijl (empirische observatie en 
definiëring van het praktijkprobleem). Het gaat om meer bewegen, een gezond voedingspatroon, waardoor een betere fysieke conditie kan worden opgebouwd, cliënten afvallen en de bloeddruk omlaag gaat. Uiteindelijk leidt dit tot een beter functioneren in de rollen die ouderen hebben in het dagelijks leven.

\section{Fase van de probleemanalyse}

Door haar patiënten te bevragen en een enquête af te nemen bij collega's kan Agnes haar probleemdefinitie bevestigen en vaststellen dat veel van haar cliënten na enige tijd terugvallen in oud gedrag, daardoor de hoop verliezen dat ze hun leefstijl kunnen veranderen (uitkomst niet gerealiseerd) en ontmoedigd raken. Als Agnes in haar probleemanalyse reflecteert op de cruciale factoren in dit probleem benoemt ze 'hoop' als een van de 'central issues' en na een zoektocht in de wetenschappelijke literatuur 'self-efficacy' als kritische concept. Dit zijn bij uitstek emancipatoire issues en concepten, want meer hoop en self-efficacy maken de cliënt vrijer om de regie over hun gezondheid in eigen hand te nemen. Met 'hoop' als central issue en 'self-efficacy' als kritisch concept kan Agnes aannames doen m.b.t. het probleem. Daarvoor moet ze zich eerst verdiepen in de literatuur en theorie over 'hoop' en 'self-efficacy'. Zo leert ze bijv. dat het begrip 'hoop' volgens het model van Snyder [8] geoperationaliseerd wordt als:

Hope $=$ Goal formulation + Path finding + Agency.

Dus hoop ontstaat pas als je een realistisch haalbaar doel kunt stellen, weet welke handelingsopties (acties) nodig zijn om het doel te verwezenlijken én ook wat je daarvoor zelf moet kunnen (zelfeffectiviteit) of moet inbrengen [8]. Anders geformuleerd: Hoop= willen en weten wat te doen en vertrouwen in eigen kunnen (Figuur 3). Self-efficacy is het vertrouwen in eigen kunnen en dat je je doelen kunt behalen [9]. Hoop en self-efficacy grijpen op elkaar aan en veronderstellen elkaar, zo leert Agnes. Ze kan met deze aannames en onderzoek in de praktijk de probleemanalyse onderbouwen. Deze luidt nu ongeveer als volgt: cliënten leren door de psycho-educatie wel welke aanpassingen nodig zijn in hun leefstijl, maar het lukt ze niet om een haalbaar doel te bedenken (doel formuleren) dat klein genoeg is om te behalen met de middelen en inzet die past bij hun persoon (zelfeffectiviteit) en die soms ook niet voldoende toegesneden zijn op het te behalen doel (Path finding). Cliënten willen teveel in één keer, houden het daarom niet vol en falen, waardoor het vertrouwen in eigen kunnen wordt gekrenkt. Uiteindelijk raken ze gedemotiveerd en verliezen ze de hoop.

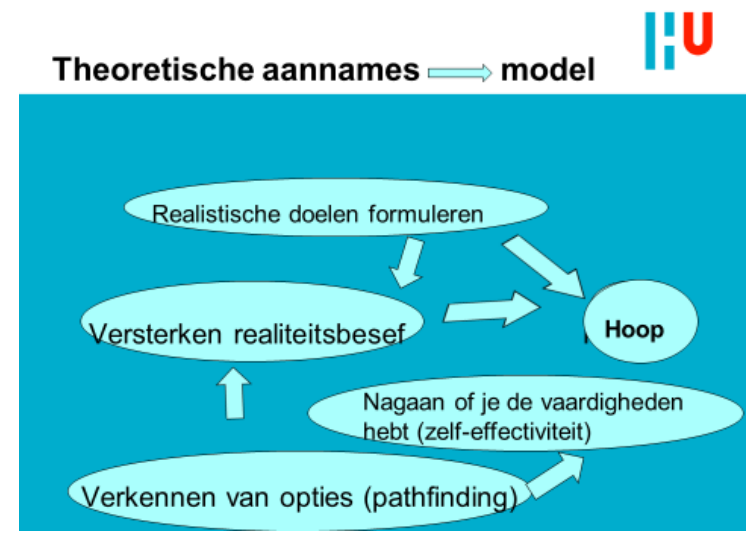

Figuur 3: Theoretische aannames model

De oplossingsrichting tekent zich voor Agnes nu af. De interventie of benadering moet cliënten helpen haalbare doelen te stellen met de daarbij horende acties die afgestemd zijn op wat ze van zichzelf weten wat ze kunnen. Met deze conclusie sluit Agnes haar probleemanalyse af en gaat ze door naar een volgende fase in haar onderzoek: het inventariseren van 
oplossingen en het selecteren van de interventie die het beste past bij de oplossingsrichting. Ook hiervoor is behalve literatuuronderzoek opnieuw praktijkonderzoek nodig om beter oplossing en interventie met elkaar te matchen.

Fase van het zoeken naar een oplossing Door middel van een literatuurstudie met het zoekformat CIMO (Context, Interventie, Mechanisme, Outcome) vindt ze een benadering die effectief is in het realiseren van uitkomsten zoals Agnes ook voor haar cliënten nastreeft: een in het dagelijks leven geïntegreerd patroon van meer bewegen en gezonder eten, leidend tot lagere bloedruk en verminderde insuline-afhankelijkheid. Het is een samengesteld interventieprogramma met een:

-psycho-educatie over leefstijl -oefengroep met leefstijl interventies -lotgenotengroep voor uitwisseling van ervaringen en bekrachtiging

Hoe kan het mechanisme van dit samengestelde interventieprogramma verklaard worden? Met andere woorden: hoe werkt het? Door de psychoeducatiecursus over leefstijl weten cliënten wat ze in hun leefstijl moeten aanpassen. Door hun deelname aan een oefengroep gaan ze hier concreet mee aan de slag en worden ze ook gecoacht in het formuleren van hun persoonlijke doel (Goal formulation) en het opstellen van een actieplan (path finding) dat gebaseerd is op een realistische inschatting en vertrouwen in eigen kunnen (Agency=self-efficacy). Door de oefeningen uit het actieplan onder begeleiding uit te voeren krijgen cliënten feedback die ondersteunend is, hen bekrachtigt en empowert. Vervolgens worden ervaringen gedeeld in een lotgenoten groep waarmee sociale steun en het proces van zin-en betekenisgeving de motivatie van cliënten verder in de gewenste richting stuurt (zie Figuur 4).

\section{Context-Interventie-Mechanisme-Outcome}

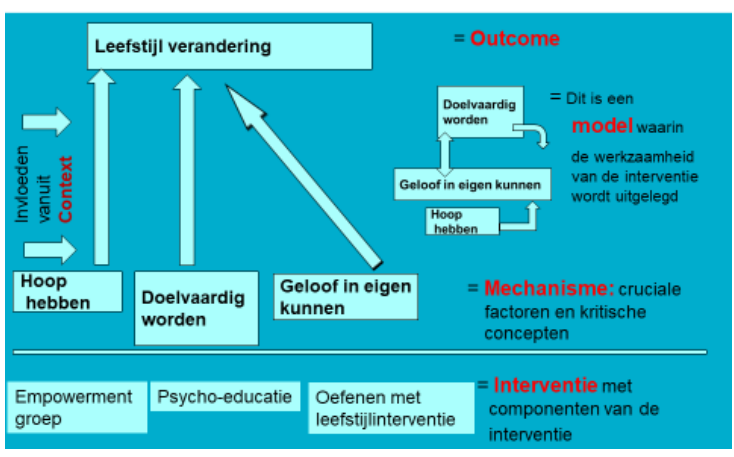

Figuur 4: componenten van de interventie

\section{Ontwerpfase}

Het mechanisme van de samengestelde interventie is het domein van het realistische (the real), maar laat nog open hoe het interventieprogramma gefinetuned moet worden of aangepast om in de context van de ouderenpoli (the actual) van Agnes kans van slagen te hebben. Het gaat om de vertaling van het interventieprogramma naar het actuele (transfer from the real to the actual). Welke voorwaarden stelt de praktijk aan de interventie? Hoe kan de interventie geactualiseerd worden? Met welke noodzakelijke aspecten moet er rekening worden gehouden? Agnes komt na nieuw praktijkonderzoek, waarin zij ook cliënten interviewde, uit op de volgende condities die zij vertaalt naar eisen aan het interventieprogramma: -de uitgangspositie van de cliënten op de poli loopt sterk uiteen qua lichamelijke conditie en cognitieve vermogens, hetgeen betekent dat de psycho-educatie een grote mate van flexibiliteit moet hebben in de aan te bieden inhoud, maar ook stelt het eisen aan het niveau van de coaching in de oefengroep. Er moeten mogelijk homogene groepen samengesteld worden. -Lettend op cognitieve beperkingen dient 
de psycho-educatiecursus

boosterbijeenkomsten te krijgen tijdens de duur van de oefengroep en lotgenotengroep (waar deze in de literatuur nog na elkaar volgend in de tijd beschreven staan). De agenda van de lotgenotengroep moet, meer dan in de literatuur beschreven wordt, gericht zijn op onderlinge positieve bekrachtiging door een structuur die uitwisseling en wederkerigheid faciliteert.

Met deze ontwerp-eisen past Agnes het interventieprogramma aan om met het resultaat een pilot te organiseren. Pas na de pilot en de eventuele bijsturing van het ontwerp van het interventieprogramma op grond van de evaluatie van de pilot besluit Agnes samen met het team waar ze deel van uitmaakt tot implementatie. De implementatie zelf zullen we hier niet bespreken. We volstaan hier met het benoemen van de noodzaak om een implementatie strategie en plan te bedenken en dat hier mogelijk ook aanvullend praktijkonderzoek voor nodig kan zijn.

Welke kansen worden benut in dit traject of met andere woorden welke potentie en onbenutte mogelijkheden kunnen worden gebruikt? De reflectie op deze vraag is een kritisch-realistische omdat voorbij het actuele wordt gekeken naar wat mogelijk zou kunnen worden gerealiseerd en misschien wel zou moeten worden gerealiseerd vanuit een emancipatoire agenda. Daarvoor kan een innovatie in de ontwerpfase aangepast worden. In deze zin komt de vraag eigenlijk nog vóór de vraag naar de noodzakelijke voorwaarden om het interventieprogramma te actualiseren. Op de poli waar Agnes werkt kon er een potentieel van elkaar willen helpen worden benut in de lotgenotengroep door aanpassingen te doen in de methodiek, waardoor cliënten een goed gevoel ontwikkelden en er een band ontstond tussen deelnemers. Dit is emancipatoir omdat het mensen eigenaar (actor) maakt van het proces om gezonder te worden i.p.v. de passieve consument te blijven van te ontvangen zorg.

\section{Discussie}

Het emancipatoire aspect van het kritisch realisme veronderstelt een visie op zorg waarvan de 'evidence' soms moeilijk in onderzoek aan te tonen is. Het gaat immers om betekenisgeving die nu eenmaal subjectief is en moeilijk te objectiveren. Hoop bijv. is een samengesteld begrip en de uitkomst van componenten zoals doelvaardigheid en zelf-effectiviteit die elk zelf ook een impact hebben op leefstijlverandering. De onderlinge relaties zijn complex. Hoewel kwantitatief onderzoek niet onmogelijk is (hoop kan bijv. gemeten worden met de Hopevragenlijst van Snyder [8]), zal onze kennis vooral van kwalitatief en mixed methods onderzoek komen. Naast het raadplegen van wetenschappelijk onderzoek zal de verpleegkundig specialist ook zelf praktijkonderzoek doen, allereerst om het probleem te analyseren en daarna om de vertaling te maken van 'the real' naar 'the actual'. Deze transfer wordt tegenwoordig steeds meer gezien als een onderdeel van kennisverwerving omtrent z.g. 'complex interventions'. In het Verenigd Koninkrijk heeft de Medical Research Council al sinds 2000 een richtlijn voor 'Developing and evaluating complex interventions' uit doen gaan [10] en deze vindt nu overal navolging [11]. Het moge duidelijk zijn dat verpleegkundig specialisten als innovator vaak van doen hebben met complexe interventies waarin verschillende domeinen van zorg (somatisch, psychosociaal, medisch en sociaal) betrokken zijn, zoals ook het geval was in de casus van Agnes. De complexiteit kan door hen het beste bestudeerd worden aan de hand van de CIMO-configuratie: Context, Interventie, 
Mechanisme en Outcome (zie Figuur 1). De CIMO is ook als format voor het zoeken in databanken geschikt om studies te vinden die het mechanisme in relatie met de context waarin de interventie uitgevoerd wordt, hebben onderzocht. In de ontwerpen implementatiefase van een innovatie speelt de CIMO-configuratie duidelijk een rol omdat het verbanden legt tussen werkzame componenten van de interventie en de outcome: hoe werkt de interventie om deze outcome te realiseren en hoe wordt het beïnvloed door context factoren? Laten we tot slot nog even terugkeren naar de discussie uit de inleiding waarin we de positivistische wens om objectieve uitspraken te doen stelden tegenover de idee dat de perspectieven van betrokkenen bepalend zijn en dat de realiteit alleen subjectief is. Het kritisch realisme neemt een tussenpositie in waar het streeft naar uitspraken over plausibele causaliteit gebaseerd op de onderzochte perspectieven. Hoe verhoudt zich dat met de CIMO-configuratie? Immers, de beïnvloedende factoren die samengevat worden als context (de $\mathrm{C}$ in CIMO) kunnen ook heel feitelijke 'harde' oorzaken betreffen die in een positivistisch onderzoek (RCT's) in een gesloten systeem gecontroleerd onderzocht zouden kunnen worden. Echter, de kritisch-realistische benadering benadrukt het sociale gedrag waartoe de feitelijke 'harde' oorzaken aanleiding geven en hoe daar door betrokkenen over gedacht wordt. Op basis daarvan kan het tendenties beschrijven. Het kritisch realisme onderkent dat sociaal gedrag en visie an sich context factoren zijn (en meegenomen moeten worden in het praktijkonderzoek). De verpleegkundig specialist uit de casus (Agnes) bijvoorbeeld had een duidelijke visie op haar vak als dat ze integrale (holistische) zorg wilde bieden. Deze visie stuurde haar in haar probleemanalyse en ook bij het zoeken naar een oplossing. Ook het perspectief van de patiënten speelde als beïnvloedende (context) factor een rol. Door cliënten te interviewen in de fase van de probleemanalyse werd het Agnes pas echt duidelijk dat (wan)hoop een cruciale factor is die het succes van een interventie meebepaalt.

\section{Conclusie}

De conclusie is dat een kritisch realistische benadering past bij innovatie en onderzoek in het kader van innovatie in de gezondheidszorg, waar geldige kennis altijd gesitueerd is in contexten. De CIMOconfiguratie helpt de verpleegkundig specialist bij het structureren van zijn/haar onderzoek. Bovendien zal het kritischemancipatoire aspect garant staan dat de kennis die ontwikkeld wordt over goede zorg ook recht doet aan het perspectief van de cliënt én dat er ook een link is met de visie op het beroepsdomein van de verpleegkundig specialist. gebracht.

\section{Referenties}

1. Sayer, A., Realism and social science SAGE. 2000, London.

2. Wilson, V. and B. McCormack, Critical realism as emancipatory action: the case for realistic evaluation in practice development. Nursing Philosophy, 2006. 7(1): p. 45-57.

3. Harré, R., The Philosophies of Science An Introductory Survey. 1972.

4. Bhaskar, R., A realist theory of science, York. 1975, Leeds Books Ltd.

5. Habermas, J., The theory of communicative action volume 2 : The critique of functional reason. McCarthy (transl.) London: Heinemann, 1987.

6. Delanty, G., Social science: Beyond constructivism and realism. 1997: 
U of Minnesota Press.

7. Boeijen, E.R.K., Laurant, M.G.H., Sitvast, J.E., Van Meijel, B. and Van Vught, A.J.A.H., PsychiatricMental Health Nurse Practitioners in the Role of

Coordinating Practitioners: A Survey Study. International Journal of Nursing and Health Care Research, 2021. 6(4) DOI: 10.29011/2688-9501.101243.

8. Snyder, C.R., Handbook of hope:

Theory, measures, and applications. 2000: Academic press.

9. Bandura, A., Efikasi-diri: The Exercise of Control. NY: Freeman \& Company, 1997.
10. Campbell, M., R. Fitzpatrick, A. Haines, A.L. Kinmonth, P. Sandercock, D. Spiegelhalter and P. Tyrer, Framework for design and evaluation of complex interventions to improve health. Bmj, 2000. 321(7262): p. 694-696.

11. Möhler, R., G. Bartoszek, S. Köpke and G. Meyer, Proposed criteria for reporting the development and evaluation of complex interventions in healthcare (CReDECI): guideline development. International journal of nursing studies, 2012. 49(1): p. 40-46. 